\title{
An Exploratory Study on the Nature and Type of Relationship in Male and Female College Students and its effect on Locus of Control and Ways of Coping
}

\author{
Aditi Shah ${ }^{1}$, Nicole Fernandes ${ }^{2}$, Fatema Sanjana ${ }^{3}$, Veena Kumar ${ }^{4}$ \\ ${ }^{1-3}$ Students, Department of Psychology, KC, College, Mumbai \\ ${ }^{4} \mathrm{Head}$, Department of Psychology, KC College, Mumbai. \\ Corresponding author: Veena Kumar \\ Email - veena_sunshine@yahoo.co.in
}

\begin{abstract}
Background: This research aims to understand the correlation and gender differences that may exist among 18 to 20 years old college students on Locus of control and Ways of Coping.

Methods: An online form (Google form) was sent to 60 participants; 30 males and 30 females, in the city of Mumbai. The Ways of Coping Questionnaire and Levenson's Multidimensional Locus of Control Inventory was administered to the study and control group. The data was statistically analyzed using Pearson's correlation and other statistics.

Results: The correlation between Internal Locus of control and Distancing Way of Coping in males was found to be significant at 0.05 level and correlation between Powerful others Locus of control and Confrontive Coping Way of Coping as well as Powerful Others Locus of control and Escape avoidance Way of coping in females were found to be significant as 0.05 level.

Conclusion: The results could be applied to everyday life settings namely schools, family, College, counselling, mental health, and Professional settings. Larger studies in diverse settings are needed.
\end{abstract}

Keywords: Locus of control, Ways of coping, gender differences, locus of control.

(Paper received $-6^{\text {th }}$ April 2018, Peer review completed $-20^{\text {th }}$ May 2018)

(Accepted $-28^{\text {th }}$ May 2018)

\section{INTRODUCTION}

"Locus of control can be defined as the extent to which people have power over events in their lives". The concept of Locus of control was developed by Julian Rotter. Locus means "place". "People with Internal locus of control believe that through their behaviour they can control the likelihood of receiving reinforces". "People with External locus of control don't see as much link between their behaviour and the likelihood of being rewarded" [1]. Hanna Levenson had a different take on the conceptualization of Locus of control. According to her, it is possible that a person may believe in both chance and in individual efforts. Levenson also stated that many people believe that powerful other people control their lives. Thus, she developed a scale to measure the internal and two external dimensions (chance and powerful others) of the locus of control concept [2].

Factors influencing Locus of control

- Family: Many internals have grown up with families modelling typical internal beliefs; these families emphasized effort, education, responsibility and thinking, and parents typically gave their children rewards they had promised them [3]. 
- Socio-economic status: Externals are typically associated with lower socio-economic status. Many researches state that rich people tend to have an internal locus of control [4].

- Political scenario: Societies experiencing social unrest increase the expectancy of being out-ofcontrol; therefore, people in such societies become more external [5].

- Age: Researches state internality may increase until middle age, decreasing thereafter [6].

- Culture: Japanese people tend to be more external in locus-of-control orientation than people in the US [7].

Coping can be defined as "constantly changing cognitive and behavioural efforts to manage specific external or internal demands that are appraised as taxing or exceeding the resources of the person" [8]. Coping, can be at both levels, conscious or/and unconscious, to solve personal and interpersonal problems, in order to reduce or deal with the stress and conflict. Whether or not a person will experience stress, depends if the person appraises the situation/stimulus as threatening or challenging. After appraising a stimulus as threatening or challenging, the person will base his/her actions on what kinds of resources' or options are available to him/her at that point in time. E.g. if a person is blocked by a robber, the person can either try to run away, or give in, or fight with the robber [8].

Locus of control to affect the appraisal process and influence the coping responses made. Internal Locus of Control individuals are less likely to report being threatened by a Stressor. Also, Internal Locus of Control (LC) individuals tend to have better coping skills than externals. Researches state, they tend to use more instrumental strategies and engage in less task-irrelevant self-preoccupation. Aspinwall and Taylor [9] believe that an internal LC leads people to adopt active coping strategies by contributing to a sense of self confidence needed to confront problems directly.

A study done states that an external locus of control orientation was significantly related to higher stress scores and lower achievement orientation. Higher achievement orientation was positively related to the use of active coping styles. Male subjects were slightly but significantly more internally oriented in terms of locus of control than female subjects [10]. In another study, regression analyses indicated that optimism and locus of control were relatively independent Predictors of control appraisals and that control appraisals were generally better Predictors of coping than either locus of control or optimism [11].

Internal LC individuals are less likely to report being threatened by a Stressor and more accepting of Stressors deemed unchangeable [12]. Internal LC individuals tend to have better coping skills than externals. They tend to use more instrumental strategies and engage in less task-irrelevant self-preoccupation [12]. A study by Takaki and colleagues [13], focused on the gender differences with relationship to internal locus of control and self-efficacy in haemodialysis patients and their compliance. This study showed that females that had high internal locus of control were less compliant in regards to their health and medical advices compared to the men that participated in this study. The internal facet of locus of control plays an important role in influencing the experiences in people's lives, suggests Klein and Warnet [14]. This study aims to determine whether there exists a relationship between Locus of Control and Ways of coping among male and female college students.

\section{Hypothesis:}

\section{METHODOLOGY}

1) There will be a correlation between Internal Locus of Control and Distancing Way of Coping amongst females.

2) There will be a correlation between Powerful Others Locus of Control and Confrontive Coping Way of Coping amongst females.

3) There will be a correlation between Powerful Others Locus of Control and Escape Avoidance Way of Coping amongst females.

4) There will be a correlation between Internal Locus of Control and Distancing Way of Coping amongst males.

5) There will be a correlation between Powerful Others Locus of Control and Confrontive Coping Way of Coping amongst males. 
6) There will be a correlation between Powerful Others Locus of Control and Escape Avoidance Way of Coping amongst males.

\section{Variables}

Since this was a correlation study, there is no Independent variable (IV) and Dependent variable (DV). Operational definitions of the variables are as follows:

Ways of Coping Questionnaire - Susan Folkman \& Richard S. Lazarus [15]

Ways Of Coping - "the range of thoughts and acts that people use to deal with the internal and/or external demands of specific stressful encounters."

Confrontive Coping - "describes aggressive efforts to alter the situation and suggests some degree of hostility and risk-taking."

Distancing - "describes cognitive effort to detach oneself and to minimize the significance of the situation."

Self-Controlling - "describes efforts to regulate one's feelings and actions."

Seeking Social Support - "describes efforts to seek informational support, tangible support and emotional support."

Accepting Responsibility - "acknowledges one's own role in the problem with a concomitant theme of trying to put things right."

Escape-Avoidance - "describes wishful thinking and behavioural efforts to escape or avoid the problem. Items on this scale contrast with those on the Distancing scale, which suggest Detachment."

Planful Problem Solving - "describes deliberate problem focused efforts to alter the situation, coupled with an analytical approach to solving problem."

Positive Reappraisal - "describes efforts to create positive meaning by focusing on personal goals. It also has a religious dimension."

Levenson's Multidimensional Locus of Control Inventory- Hanna Levenson [16]

Locus of control: "It refers to where a person places the primary causation of events in his/her life; whether or not he/she feels that he/she is in control of their outcomes"

Internal Locus of control - "an individual's belief that they control their own lives."

Powerful Others Locus of control - "the individual believes in an ordered world controlled by powerful others-such as political leaders, parents or God"

Chance Locus of control - "the individual considers the world as unordered and chaotic"

\section{Controls:}

- Participants answering the scales belonged to the age group of 18-20 years (Males \& Females)

- All were residents of Mumbai City.

- All participants were English literate.

- They all were college students.

- Randomly chosen sample.

\section{Sample:}

- 60 participants, 30 males and 30 females

- Age group- 18 to 20 years old.

- College going students from different streams.

- Residents of Mumbai city.

\section{Apparatus and Material:}

The Scales used are as follows:

Ways of Coping Questionnaire - Susan Folkman \& Richard S. Lazarus [15]. It contains 66 items. WAYS can assess and identify thoughts and actions that individual uses to cope with the stressful encounters of everyday life. Its 8 subscales are: Confronting coping, distancing, self-controlling, seeking social support, accepting responsibility, escape avoidance, planned problem solving and positive appraisal. Psychometric 
properties (e.g.-validity and reliability) have been established by over 25 years of research across a wide array of populations and methodologies. The reliability was in the range of 0.06 to 0.08 for all the eight subscales which is moderate to high correlation [17-18]. In the clinical setting, the WAYS can help clients develop practical coping skills by evaluating their coping process (including strengths and weaknesses) and offer alternative coping mechanisms. It has the following subscales - Confrontive Coping, Distancing, SelfControlling, Seeking Social Support, Accepting Responsibility, Escape-Avoidance, Planful Problem Solving and Positive Reappraisal.

Levenson's Multidimensional Locus of Control Inventory - The Levenson scale uses a Liker type rating system. The scale asks the participant to interpret their own specific experience. It has less ambiguous wording. There is extremely low social desirability bias in the Levenson scale. Internal consistency reliability was satisfactory; alpha above 0.70 . This scale was validated by its creator, who found that participants who rated high on the $C$ scale shared traits that could not be distinguished by the I or P scales, thus confirming the usefulness of the multidimensional approach. The subscales are Internal, Chance, Powerful Others [19].

Design: A repeated measures design was used, as each participant responded to each of the questionnaire (i.e. Ways of Coping \& Multidimensional Locus of Control) respectively.

Procedure: An online Google form was distributed to 30 males and 30 females respectively in the age group of 18 to 20 years; keeping in mind the controls of the study. Participants were assured of the confidentiality regarding their responses. The data was recorded and further statistical analysis was done using Microsoft Excel Program. Various theoretical perspectives were used to explain the results of the study.

\section{RESULTS AND DISCUSSION}

The present research examines the correlation and gender differences that may exist among 18 to 20 years old college students on Locus of control and Ways of Coping. The Correlation coefficient was calculated using the Pearson Product Moment and the Formula for which was

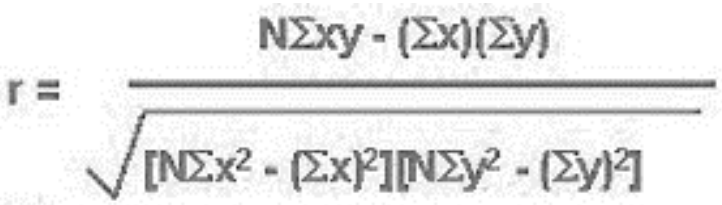

Descriptive statistic refers to summarizing and describing the data collected from sample. (Table 1). Inferential Statistics help us to draw conclusions from the data i.e. whether conclusions the obtained data is due to chance or true correlation. Correlation statistical technique was used to understand the degree and relation between two variables. It shows the magnitude and direction between the two variables. Correlation Coefficient is the numerical index that expresses the relationship; it tells us the extent to which the two variables are correlated. A positive correlation means as one variable changes, there is corresponding change in the other variable in the same direction. Whereas in a negative correlation, the two variables are inversely related i.e. as one variable changes, there is a corresponding change in other variable in the opposite direction. Degree of freedom refers to the number of observations that are allowed to vary after statistics have been calculated. Level of significance refers to the extent to which the researcher is willing to attribute the result within chance and correlation.

There will be a correlation between Internal Locus of Control and Distancing Way of Coping amongst females. The Correlation ( $r$ ) obtained was 0.19 , indicating a positive low correlation. However, with reference to statistical table of correlation the data was found to be not significant which indicates that the obtained correlation was more due to chance and less due to true correlation.

As understood from the cognitive perspective, females may believe that events happening in their life are in their control, may distance themselves from the distressful situation, as they are more likely to believe that they do have a choice to distance themselves. 
Table 1: Summary of descriptive statistics of Females

\begin{tabular}{|l|l|l|l|l|}
\hline FEMALES & Sum & Mean & Range & SD \\
\hline Internal LOC & 1057 & 35.23 & 26 & 6.36 \\
\hline Powerful Others LOC & 570 & 19.00 & 37 & 9.02 \\
\hline Chance LOC & 699 & 23.30 & 33 & 8.79 \\
\hline Confrontive Coping & 245 & 8.17 & 12 & 3.06 \\
\hline Distancing & 251 & 8.37 & 16 & 3.45 \\
\hline Self Controlling & 353 & 11.77 & 10 & 3.26 \\
\hline Seeking Social Support & 264 & 8.80 & 18 & 4.33 \\
\hline Accepting Responsibility & 198 & 6.60 & 10 & 2.46 \\
\hline Escape Avoidance & 333 & 11.10 & 19 & 4.93 \\
\hline Planful Problem Solving & 292 & 9.73 & 14 & 3.68 \\
\hline Positive Reappraisal & 366 & 12.20 & 18 & 4.47 \\
\hline
\end{tabular}

Table 2: Summary of descriptive statistics of Males

\begin{tabular}{|l|l|l|l|l|}
\hline MALES & Sum & Mean & Range & SD \\
\hline Internal LOC & 1119 & 37.3 & 24 & 5.15 \\
\hline Powerful Others LOC & 582 & 19.4 & 35 & 9.62 \\
\hline Chance LOC & 725 & 24.17 & 32 & 9.24 \\
\hline Confrontive Coping & 308 & 10.27 & 13 & 3.32 \\
\hline Distancing & 315 & 10.5 & 14 & 3.66 \\
\hline Self Controlling & 387 & 12.9 & 14 & 3.51 \\
\hline Seeking Social Support & 313 & 10.43 & 18 & 4.46 \\
\hline Accepting Responsibility & 231 & 7.7 & 8 & 2.02 \\
\hline Escape Avoidance & 385 & 12.83 & 18 & 4.36 \\
\hline Planful Problem Solving & 339 & 11.3 & 15 & 3.71 \\
\hline Positive Reappraisal & 420 & 14 & 15 & 3.99 \\
\hline
\end{tabular}

Table 3: Summary of descriptive statistics of Locus of control and Ways of Coping

\begin{tabular}{|l|l|l|l|l|}
\hline Variable & Total & Mean & Range & SD \\
\hline Internal LOC & 2176 & 36.27 & 27 & 5.83 \\
\hline Powerful Others LOC & 1152 & 19.2 & 37 & 9.25 \\
\hline Chance LOC & 1424 & 23.73 & 35 & 8.95 \\
\hline Confrontive Coping & 553 & 9.22 & 14 & 3.34 \\
\hline Distancing & 566 & 9.43 & 10 & 3.68 \\
\hline Self Controlling & 740 & 12.33 & 14 & 3.40 \\
\hline Seeking Social Support & 577 & 9.62 & 18 & 4.44 \\
\hline $\begin{array}{l}\text { Accepting } \\
\text { Responsibility }\end{array}$ & 429 & 7.15 & 11 & 2.30 \\
\hline Escape Avoidance & 718 & 11.97 & 22 & 4.70 \\
\hline Planful Problem Solving & 631 & 10.52 & 15 & 3.74 \\
\hline Positive Reappraisal & 786 & 13.1 & 18 & 4.30 \\
\hline
\end{tabular}

According to the evolutionary perspective, one of the typical ways humans deal with distressing situation is distancing which is a form of withdrawal; as a way to enhance and protect oneself from perceived dangerous stimuli. From a socio-cultural context, in India women generally occupy a secondary status and hence may feel not powerful enough to fight the overwhelming (eustress, or generally distress) stimuli. 
Table 4: Summary of Correlation data

\begin{tabular}{|c|c|c|c|c|c|c|}
\hline \multirow[t]{2}{*}{$\mathrm{R}$} & \multicolumn{4}{|c|}{$\begin{array}{l}\mathrm{N}=30 \text { males, } 30 \text { Females. } \\
\mathrm{df}=28\end{array}$} & \multicolumn{2}{|l|}{$\begin{array}{l}\mathrm{n}=60 \\
\mathrm{df}=58\end{array}$} \\
\hline & Males & $\mathrm{p}<$ & Females & $\mathrm{p}<$ & Controls & $\mathrm{p}<$ \\
\hline $\begin{array}{l}\text { Internal LOC \& Confrontive } \\
\text { Coping }\end{array}$ & -0.02 & NS & 0.11 & NS & 0.10 & NS \\
\hline Internal LOC \& Distancing & -0.38 & $\mathrm{p}<0.05$ & 0.19 & NS & -0.02 & NS \\
\hline Internal LOC \& Self controlling & -0.24 & NS & 0.24 & NS & 0.04 & NS \\
\hline $\begin{array}{l}\text { Internal LOC \& Seeking Social } \\
\text { Support }\end{array}$ & 0.06 & NS & 0.33 & NS & 0.23 & NS \\
\hline $\begin{array}{l}\text { Internal LOC \& Accepting } \\
\text { Responsibility }\end{array}$ & -0.06 & NS & -0.21 & NS & -0.10 & NS \\
\hline $\begin{array}{l}\text { Internal LOC \& Escape } \\
\text { Avoidance }\end{array}$ & -0.28 & NS & -0.04 & NS & -0.10 & NS \\
\hline $\begin{array}{l}\text { Internal LOC \& Planful } \\
\text { Problem Solving }\end{array}$ & 0.08 & NS & 0.35 & NS & 0.26 & NS \\
\hline $\begin{array}{l}\text { Internal LOC \& Positive } \\
\text { Reappraisal }\end{array}$ & -0.07 & NS & 0.28 & NS & 0.16 & NS \\
\hline $\begin{array}{l}\text { Powerful Others LOC \& } \\
\text { Confrontive Coping }\end{array}$ & 0.18 & NS & 0.39 & $\mathrm{p}<0.05$ & 0.27 & NS \\
\hline $\begin{array}{l}\text { Powerful Others LOC \& } \\
\text { Distancing }\end{array}$ & 0.19 & NS & 0.14 & NS & 0.17 & NS \\
\hline $\begin{array}{l}\text { Powerful Others LOC \& Self } \\
\text { controlling }\end{array}$ & 0.28 & NS & 0.25 & NS & 0.27 & NS \\
\hline $\begin{array}{l}\text { Powerful Others LOC \& } \\
\text { Seeking Social Support }\end{array}$ & 0.12 & NS & 0.29 & NS & 0.20 & NS \\
\hline $\begin{array}{l}\text { Powerful Others LOC \& } \\
\text { Accepting Responsibility }\end{array}$ & 0.01 & NS & 0.30 & NS & 0.16 & NS \\
\hline $\begin{array}{l}\text { Powerful Others LOC \& Escape } \\
\text { avoidance }\end{array}$ & 0.23 & NS & 0.40 & $\mathrm{p}<0.05$ & 0.32 & NS \\
\hline $\begin{array}{l}\text { Powerful Others LOC \& Planful } \\
\text { Problem Solving }\end{array}$ & -0.04 & NS & 0.04 & NS & 0.01 & NS \\
\hline $\begin{array}{l}\text { Powerful Others LOC \& } \\
\text { Positive Reappraisal }\end{array}$ & 0.07 & NS & 0.32 & NS & 0.20 & NS \\
\hline $\begin{array}{l}\text { Chance LOC \& Confrontive } \\
\text { Coping }\end{array}$ & 0.08 & NS & 0.21 & NS & 0.15 & NS \\
\hline Chance LOC \& Distancing & 0.13 & NS & 0.20 & NS & 0.17 & NS \\
\hline Chance LOC \& Self Controlling & 0.22 & NS & 0.04 & NS & 0.14 & NS \\
\hline $\begin{array}{l}\text { Chance LOC \& Seeking Social } \\
\text { Support }\end{array}$ & 0.34 & NS & 0.09 & NS & 0.23 & NS \\
\hline $\begin{array}{l}\text { Chance LOC \& Accepting } \\
\text { Responsibility }\end{array}$ & 0.08 & NS & 0.18 & NS & 0.14 & NS \\
\hline $\begin{array}{l}\text { Chance LOC \& Escape } \\
\text { Avoidance }\end{array}$ & 0.12 & NS & 0.16 & NS & 0.15 & NS \\
\hline $\begin{array}{l}\text { Chance LOC \& Planful } \\
\text { Problem Solving }\end{array}$ & 0.14 & NS & -0.13 & NS & 0.02 & NS \\
\hline $\begin{array}{l}\text { Chance LOC \& Positive } \\
\text { Reappraisal }\end{array}$ & 0.22 & NS & 0.10 & NS & 0.16 & NS \\
\hline
\end{tabular}


Looking from behaviouristic perspective, her distancing rewards her feeling of less threatened which in turn would maintain the behaviour that she has the power to at least distance. There will be a correlation between Powerful Others Locus of Control and Confrontive Coping Way of Coping amongst females.

The Correlation ( $\mathrm{r}$ ) obtained was 0.39 , indicating a positive moderate correlation. With reference to statistical table of correlation the data was found to be significant at 0.05 level, which means that the obtained data was more due to true correlation and less due to chance.

This may be due to:

- From socio-cultural point of view, Since India has a collectivistic culture, there is a tendency amongst Indians to attribute responsibility to others and hence engage in confrontive way of coping. As a result, we might engage in blame games rather than proactive behaviour. And along with this, in Indian context, since women may not engage in an active role, as a result of which, she is more likely to follow orders, hence as a consequence the responsibility lies with the powerful other and the expected outcome may not match the real outcome. And therefore women, in a subtle way, engage in confronting by bring it to the notice of powerful other.

- According to the behaviourist perspective, In the recent past, Indians seem to idealize and imitate the western culture which engages in active and open confrontation (assertiveness practiced) ways of coping in dealing with perceived powerful others in that situation. Hence, with improved human rights laws, women may actively engage in confrontive way of coping.

There will be a correlation between Powerful Others Locus of Control and Escape Avoidance Way of Coping amongst females. The Correlation ( $\mathrm{r}$ ) obtained was 0.40 , indicating a positive moderate correlation. With reference to statistical table of correlation the data was found to be significant at 0.05 level, which means that the obtained data was more due to true correlation and less due to chance.

This may be due to:

- According to the cognitive perspective, women may choose to escape the stressful situation, as they feel the power lays in the hands of powerful others and responsibility lies with them.

- From the socio-cultural viewpoint, In Indian context woman are likely to be considered subordinate to men, thus they may be expected to not question the powerful other and the easiest and effective way to deal with this may be escaping in form of denial, wishful thinking or physically.

There will be a correlation between Internal Locus of Control and Distancing Way of Coping amongst males. The Correlation ( $\mathrm{r}$ ) obtained was -0.38 , indicating a negative moderate correlation. With reference to statistical table of correlation the data was found to be significant at 0.05 level, which means that the obtained data was more due to true correlation and less due to chance.

This may be due to:

- Being high on internal, they may feel powerful enough to deal with the situation in a "manly" way. Hence, cognitively as well as physically they would deal with the challenging situation in a direct way.

- From the socio-cultural perspective, in India, men may be considered as the problem solvers as well as heading the family, thus they may feel powerful enough and hence the responsibility falls on them and they may also initiate taking responsibility on themselves, therefore they face life's reality directly.

- Along with this, Males occupy a primary or privileged position and status in society and therefore expected to fulfil the role of being a 'powerful' man.

There will be a correlation between Powerful Others Locus of Control and Confrontive Coping Way of Coping amongst males. The Correlation ( $\mathrm{r}$ ) obtained was 0.18 , indicating a positive low correlation. However, with reference to statistical table of correlation the data was found to be not significant which indicates that the obtained correlation was more due to chance and less due to true correlation.

This may be due to:

- Looking from a socio-cultural viewpoint, as Indians we have adopted a collectivistic culture; we attribute the responsibilities to others and engage in confrontive way of coping. As a result, we may keep blaming others.

- Along with this, in Indian Society men may occupy a primary or a privileged position and status and hence they may feel powerful enough to confront others responsible for the stimuli. 
There will be a correlation between Powerful Others Locus of Control and Escape Avoidance Way of Coping amongst males. The Correlation ( $\mathrm{r}$ ) obtained was 0.23 , indicating a positive low correlation. However, with reference to statistical table of correlation the data was found to be not significant which indicates that the obtained correlation was more due to chance and less due to true correlation.

- According to the socio-cultural perspective as India has a collectivistic culture, there is a tendency among Indians to contribute responsibility to others and probably find escaping as the easiest and effective strategy at that point of time.

- From the evolutionary perspective, one of the typical ways humans deal with problems is by withdrawing, a form of distancing; as a way to enhance and protect oneself from perceived dangerous stimuli.

\section{Future Scope of the study}

- Larger sample size.

- Other statistical analysis e.g. Regression analysis, ANOVA, t-test, non-parameters can be used to understand the nature of the variable better.

- Other comparisons like age group differences, socio-cultural differences, religious differences, various faculties, inter-generational differences, longevity, sibling differences and demographic variables can be done.

- Face to face distributions of questionnaires, Interviews can be done as an additional data collection mode

- Relationship with several other variables namely Decision making, Self esteem, Cognitive appraisal, attachment styles etc can be done.

- Within each gender, intra comparison can be done with three types of locus of control and with eight subscales for ways of coping (e.g. in males internal and confrontive coping compared with powerful others and confrontive coping with chance and confrontive coping. Similarly, for females.)

\section{CONCLUSION}

The results indicated that the correlation between Internal Locus of control and Distancing Way of Coping in males was found to be significant at 0.05 level and correlation between Powerful others Locus of control and Confrontive Coping Way of Coping as well as Powerful Others Locus of control and Escape avoidance Way of coping in females were found to be significant as 0.05 level. Whereas the remaining variable combinations were found to be not significant at any of the accepted levels in psychology.

\section{REFERENCES}

1. Wallston KA. Hocus-pocus, the focus isn't strictly on locus: Rotter's social learning theory modified for health. Cogn Ther Res 1992;16(2):183-99.

2. Lefcourt HM. Locus of control: Current trends in theory \& research. Psychology Press; 2014.

3. Noor NM. Work-family conflict, locus of control, and women's weil-being: tests of alternative pathways. J Soc Psychol 2002;142(5):645-62.

4. Heaven PC. Economic locus of control beliefs and lay attributions of poverty. Austr J Psychol 1989;41(3):31525.

5. Hui CC. Locus of control: A review of cross-cultural research. Int J Intercult Relat 1982;6(3):301-23.

6. Schneider A, Körner T, Mehring M, Wensing M, Elwyn G, Szecsenyi J. Impact of age, health locus of control and psychological co-morbidity on patients' preferences for shared decision making in general practice. Patient Educ Couns 2006;61(2):292-8.

7. Mueller SL, Thomas AS. Culture and entrepreneurial potential: A nine country study of locus of control and innovativeness. J Business Venturing 2001;16(1):51-75.

8. Koole SL. The psychology of emotion regulation: An integrative review. Cogn Emot 2009;23(1):4-11. 
9. Aspinwall LG, Taylor SE. Modeling cognitive adaptation: A longitudinal investigation of the impact of individual differences and coping on college adjustment and performance. J Personal Soc Psychol 1992;63(6):989-95.

10. Phillips JM, Gully SM. Role of goal orientation, ability, need for achievement, and locus of control in the selfefficacy and goal--setting process. J Appl Psychol 1997;82(5):792-9.

11. Kostka T, Jachimowicz V. Relationship of quality of life to dispositional optimism, health locus of control and self-efficacy in older subjects living in different environments. Qual Life Res 2010;19(3):351-61.

12. Krause N, Stryker S. Stress and well-being: The buffering role of locus of control beliefs. Soc Sci Med 1984;18(9):783-90.

13. Takaki J, Yano E. Possible gender differences in the relationships of self-efficacy and the internal locus of control with compliance in hemodialysis patients. Behav Med 2006;32(1):5-11.

14. Klein J, Wasserstein-Warnet M. Predictive validity of the locus of control test in selection of school administrators. J Educ Admin 2000;38(1):7-25.

15. Scherer RF, Luther DC, Wiebe FA, Adams JS. Dimensionality of coping: Factor stability using the ways of coping questionnaire. Psychol Rep 1988;62(3):763-70.

16. Pavalache-Ilie M, Unianu EM. Locus of control and the pro-environmental attitudes. Proc Soc Behav Sci 2012;33:198-202.

17. Parker JD, Endler NS, Bagby RM. If it changes, it might be unstable: Examining the factor structure of the Ways of Coping Questionnaire. Psychol Assess 1993;5(3):361-9.

18. Lundqvist LO, Ahlström G. Psychometric evaluation of the Ways of Coping Questionnaire as applied to clinical and nonclinical groups. J Psychosom Res 2006;60(5):485-93.

19. Holder EE, Levi DJ. Mental health and locus of control: SCL- 90- R and Levenson's IPC scales. J Clin Psychol 1988;44(5):753-5.



